\title{
WATER-COPPER NANOFLUID APPLICATION IN AN OPEN LOOP PULSATING HEAT PIPE
}

\author{
Roger R. Riehl, Nadjara dos Santos \\ National Institute for Space Research - INPE - Space Mechanics and Control Division-DMC \\ Av dos Astronautas 1758, 12227-010 - São José dos Campos, SP - Brazil \\ Phone: 5512 8121-2112 / Fax: 5512 3945-6226 - Email: roger.riehl@itelefonica.com.br
}

\begin{abstract}
Several investigations have pointed the operation behavior of passive thermal control devices such as loop heat pipes (LHPs) and pulsating heat pipes (PHPs) in the past, which have cleared many points related to their design. However, an interesting aspect related to passive thermal control devices that operated by means of capillary forces to pump the working fluid have gained attention during the last years, which is in regard to the use of nanofluids on such devices. Nanofluids are known as regular fluids with addition of solid nanoparticles with sizes (diameter) below $40 \mathrm{~nm}$, which are used to enhance the working fluid's thermal performance by enhancing its thermal conductivity. Previous works have demonstrated that the liquid's thermal conductivity can be enhanced by $20 \%$ if nanoparticles are added on a concentration of $5 \%$ by mass. PHPs operate by the dynamics of slug/plug formation removing heat from a high temperature source and dissipating in a low temperature sink and are highly influenced by the bubble critical diameter related to a specific working fluid. Thus, an experimental open loop PHP (OLPHP) was tested with watercopper nanofluid, with an addition of $5 \%$ by mass of copper nanoparticles. Improvements on the overall device's operation have been observed when using the nanofluid with lower temperatures, as well as a direct influence on the thermal resistances throughout the PHP. Further analysis has shown that the addition of solid nanoparticle on the working fluid has directly contributed for the improvement of the OLPHP thermal performance.
\end{abstract}

\section{Introduction}

Nanofluid application is a recent area of investigation with promising results for thermal control systems. Basically, nanofluids are working fluids that have just started been applied in thermal system devices, using nanoparticles of solid materials used to improve the fluids' thermal conductivity. By adding 5\% of the working fluid mass with nanoparticles, the liquid thermal conductivity can be increased by up to $20 \%$ (Koo and Kleinstreuer, 2004). Some researches have already presented important contributions using nanofluids usually composed of water and copper nanoparticles with sizes around 25 nm (Koo and Kleinstreuer, 2004; Chein and Huang, 2005), which all represent the recent advances on this new and innovating technology. Investigations performed so far have pointed to the potential in using nanofluids in several thermal control applications with great improvement on the heat transfer coefficient, especially when liquid singlephase thermal control has been used. It is important, however, to mention that investigations performed so far utilizes regular pumping devices to transport the nanofluid throughout the loop (Park and Jung, 2007). However, very little is known about nanofluids application in devices such as loop heat pipes (LHPs) that require the generation of capillary forces to drive the working fluid (. In this last case, the capillary evaporator presents a porous wick structure with fine pores and the interaction with the nanofluid needs to be better investigated. The nanofluid is composed of a pure substance, like water, with solid nanoparticles usually mixed with mass fractions from 1 to $5 \%$. The nanoparticles are materials with size below $100 \mathrm{~nm}$ in diameter and should be as pure as possible to avoid any kind of chemical reaction of the substance that has been mixed. Investigations have already presented the increase on the liquid thermal conductivity of the nanofluid when compared with the pure substance by as much as $20 \%$ (depending on the nanoparticle material) when a mass fraction of up to $5 \%$ of nanoparticle was added (Koo and Kleinstreuer, 2004).

\section{Experimental results and discussion}

The PHP was operated without pre-conditioning procedures. Prior to start the skin heater placed on the evaporation section, the fan on the condensation section was turned on and kept this way until 
the end of the test. The test rig was placed on a controlled temperature environment, being kept between 18 and $20{ }^{\circ} \mathrm{C}$.

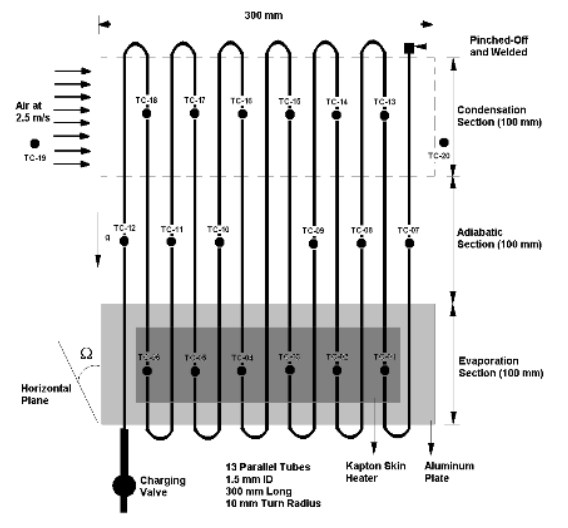

Figure 1 - Experimental setup for the open loop PHP.

Figure 2 presents a comparison between the experimental tests with the PHP operating with pure deionized water and the nanofluid at horizontal orientation. It is important to observe that with the pure water, the PHP did not present the great pulsations that are characteristics of this device, even though it was fully operational. However, with the addition of solid copper nanoparticles, the pulsations started appearing at $40 \mathrm{~W}$ and became more evident at $50 \mathrm{~W}$ with amplitudes around 5 ${ }^{\circ} \mathrm{C}$ on the evaporation section, $22{ }^{\circ} \mathrm{C}$ on the adiabatic section and $23{ }^{\circ} \mathrm{C}$ on the condensation section. It could also be observed that the mean evaporation section temperature when using the nanofluid stabilized around $90{ }^{\circ} \mathrm{C}$ for $50 \mathrm{~W}$ while for the same operation condition when using pure water was around $118^{\circ} \mathrm{C}$. In general, the evaporation temperatures when using the nanofluid were lower than when using deionized water.
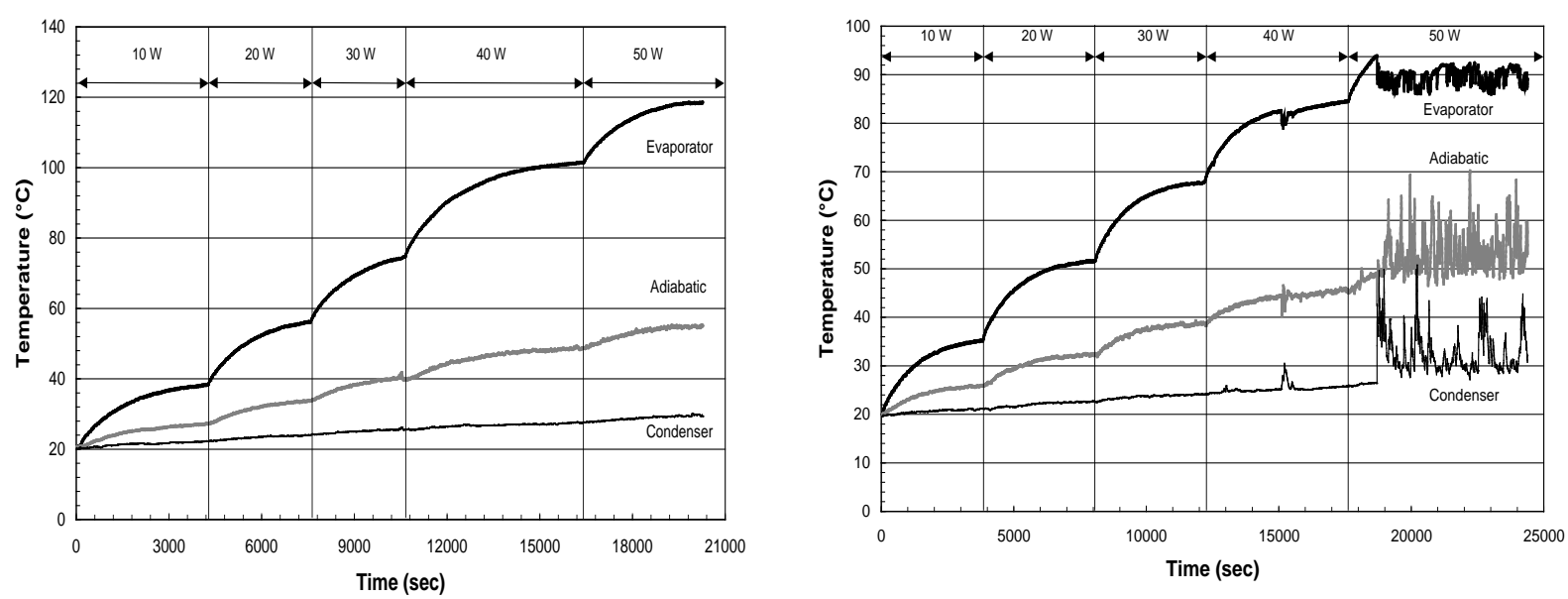

Figure 2 - Experimental results for the PHP at horizontal orientation: (a) pure water and, (b) water-copper nanofluid.

\section{References}

Chein, R., Huang, G., Analysis of microchannel heat sink performance using nanofluids, Applied Thermal Engineering Vol. 25, pp 3104-3114, 2005.

Koo, J., Kleinstreuer, C., A new thermal conductivity model for nanofluids, Journal of Nanoparticle Research, Vol. 6, pp. 577-588, 2004.

Park, K. J., Jung, D., Enhancement of nucleate boiling heat transfer using carbon nanotubes, Int. J. Heat and Mass Transfer, Vol. 50, pp. 4499-4502, 2007. 